\title{
Estimating the Incidence of Water Related Diseases: the case of Neglected Tropical Diseases in Rural Nigeria
}

\author{
Temitayo Adenike Adeyemo, Bolarinwa Titus Omonona \\ Department of Agricultural Economics, University of Ibadan, Nigeria
}

\begin{abstract}
Water-related neglected tropical diseasesare endemic among rural and farming households in Nigeria. The burden of these diseases on farm families and the society as a whole has not been fully appreciated as a result of limited empirical evidence of the incidence of the diseases at household level. This paper examined the incidence of four water-related neglected tropical diseases in rural Nigeria using data from the National Demographic and Health survey of 2008. Descriptive statistics were used to profile the incidence of the diseases across household socioeconomic and water/sanitation characteristics with the aim of linking water use and sanitation dynamics with the incidence of the identified water related Neglected Tropical Diseases (NTDS). The results showed that NTDs were endemic among rural households in northern Nigeria. The NTDs were also highest among the poorest households, with low levels of formal education. Water-related factors that predisposes rural farm families to the diseases were source of drinking water, water treatment methods andsanitation type. It is recommended that sustainable water supply based on inclusive participation of all stakeholders be put in place to forestall the spread of the disease among rural households in Nigeria.
\end{abstract}

Keywords: incidence, water-related, neglected tropical diseases, rural, Nigeria

\section{Introduction}

Water-related diseases in general have been reported to have led to the death of millions of people over the world, [1]. They occur in situations of inadequate access to good quality water and sanitation for household use, leading to an estimated over $80 \%$ of all diseases in developing countries [2].They occur directly or indirectly as a result of exposure to unwholesome water and sanitation facilities [3].There have been effort to combat some of the more renowned water-related disease with potential for epidemic such as cholera, viral hepatitis A, dysentery and typhoid [4]. Locally prevalent disease to the tropics are largely not given priority, even though they cause high levels of morbidity and social exclusions. Because water-related diseases in general occur in areas with poor water supply, poor sanitation among the poorest population in most countries,[5] there is an intrinsic neglect of these diseases to the continued detriment of the neglected communities. However, the neglect of these diseases is prevalent among specific tropical diseases called Neglected Tropical diseases.

Neglected Tropical Diseases (hereafter referred to as NTDs) are a group of parasitic and bacterial infections common to the low income populations around the world, and affecting more than a billion of the world's population (Centre for Disease Control , [6]. They are especially endemic to the poor population in Africa, Asia and the Americas [7] and have a great deal of negative impact on health and development of the population affected, [8]. In Africa, onchocerciasis alone has been reported to affect up to 37miilion people over 34 countries, [9]. The World Health Organization [10] has classified the NTDs into a list of 17. The most common of the NTDs include roundworm infection, hook worm infection, trichuriasis (whip worm infection), schistosomiasis (liver/snail fluke), lymphatic filiarisis (elephantiasis), trachoma, oncocerchiasis(river blindness),leishmaniasis, changas disease; leprosy, human African trypanosomiasis, Dracunculiais(guinea worm disease) and buruli ulcer, [11] . The World Health Organization also includes the following diseases as part of the NTDs: cysticercosis, echinococcosis, dengue fever, fascioliasis, rabies and yaws as well as neglected conditions of snake bite, [10].

Neglected tropical diseases are so called because the prevalence and economic burden are most common among the poorest and voiceless population around the world. This is usually made up of the rural, subsistent farm families and the slum dwellers in overpopulate urban cities [8]; thus their management and treatment are largely neglected. In comparison to HIV/AIDS and malaria, the NTDs receive very little attention in terms of public health issues [12]; however, they have been known to aggravate the illnesses from HIV/AIDS, tuberculosis and malaria, [13]. NTDs reduce well-being in terms of health, social and economic development, intellectual development as well as national development. The incidence of these diseases leads to social exclusiveness and attendant loss in productive capacity of the patient, [14]. Although these diseases do not have such high mortality rates, they are implicated in causing high level of morbidity and healthy life lost as measured with the DALY (Disability Adjusted Life Year) among the sufferers [15]. However, they invariably 
lead to death when they go undetected and untreated, [16]. The reduction in the productivity of sufferer and care takers also leads to enormous economic losses, both for the family and the community as a whole.

It is noteworthy that a sizable proportion of the identified NTDs are typically water-related, thriving in areaswhere access to water and good sanitation are lacking such as in rural and poor farming communities, [17].The prevalent water-related Neglected Tropical Diseases that have been ravaging Nigeria over time include, round worm, lymphatic filiaris (elephantiasis), schistosomiasis (liver fluke), onchocerciasis (river blindness) anddracunuliasis (guinea worm). The tragedy of these water-related NTDs is that they are endemic to areas of high poverty levels, thereby making the vicious cycle of poverty and disease more prevalent. In general, water-related diseases account for over $80 \%$ of deaths, especially that of infant in Africa [18]. This is as a result of ingestion of contaminated food, bites by water based vectors, as well contact with disease-causing organisms that reside polluted water sources. Over the years, access to portable water has been on the decrease in Nigeria, especially in the rural areas $[19 ; 20]$. Sources of water, both for drinking and other domestic uses have literally been sourced from open wells and streams [21]. Moreover, water from these sources are usually not subjected to treatment for safe use in the rural households. Furthermore, poor sanitation that characterizes most rural households compromise the water sources. In most cases, rural dwelling lack inbuilt sanitation facilities, thus, defeacation, bathing and other bodily functions are carried out in the streams with the belief that the flowing stream will wash them away. These actions have led to the pollution of water sources, such that transmission of organisms that carry the NTDs become common place.

The effect of the NTDs on rural economy might more easily be conceived in terms of the economic burden of the control and treatment of outbreaks of the diseases. Although, there have been efforts to capture the incidence and economic burden of the water-related NTDs on national basis over the years, there has been limited data on disaggregated household level data to this effect. Thus, the economic burdens on the individual households who have been affected directly or indirectly by the diseases are not often put in consideration, [11]. The economic impacts of these diseases are not limited to loss of productivity. They also include considerable out of pocket costs for treatment and loss of assets on other cases. Some of the times, the coping mechanisms among affected households lead to more economic problems such as low savings, low purchasing power and investment.

Despite the increasing aids to other debilitating diseases such as tuberculosis, HIV/AIDS and malaria, there is still a growing neglect of the water-related NTDs in rural Nigeria. There have been efforts over the years as regards some of the more prevalent NTDs in Nigeria, the coverage is very low. For example, the Bill and Melinda Gates Foundation supported the control of four water-related NTDs;lymphatic filiaris (elephantiasis), onchocerciasis (river blindness), trachoma and schistosomiasis in Northern Nigeria. Also, in Northern, Nigeria, there had been efforts to combat the development and spread of Trachoma and Onchocerciasis in children by the Nigerian Government and an NGO - Sightsavers International. There has also been a development of a national blue print for combating NTDs and the effects by the Federal Government of Nigeria with the aim of reducing the prevalence of NTDs by the year 2020 [22].The inclusion of NTDs and water borne diseases in the recent Sustainable Development Goals (SDGs) is a pointer to the renewed recognition and need for management of the water-related NTDs across countries. However, there is little evidence of the incidence of the waterrelated NTDs across household level characteristics in Nigeria. A good knowledge of the incidence of diseases and their burden is key to formulating effective policy direction. This study therefore examines the incidence of water-related NTDs among rural households in rural Nigeria as well as explore the effects of water/sanitation facilities on the incidence of the NTDs.

\section{Review Of Literature}

\subsection{Review of Water-Related Neglected Tropical Diseases}

In general, water-related disease have the inadequacy of portable water supply and sanitation as a common theme. However, they are broadly classified into four as water-borne diseases, water-based diseases, water-related vector diseases and water-scarce diseases [23].Water-borne diseases are those caused when humans come in contact with water that has been contaminated by waste. These pollutions are a result of use of water for waste disposal, as well as sanitary facility and the subsequent use for domestic purposes as witnessed in many rural communities. Farmers are also more susceptible to these diseases when contaminated sewage is used for fertilizers. Diseases in this class include cholera, typhoid, bacillary dysentery, infective hepatitis and Giardiasis. Water-borne diseases can be controlled by the provision and enforcement of proper sanitation facilities and provision of clean water supple for household uses.

On the other hand, water-based diseases are a result of infection by aquatic organisms with part of their life cycle in water and the rest as animal parasites. Infections by water-based diseases come as a result of humancontact with the organism while in the water or consumption of animals with the organisms still active within them. The proliferation of these organisms occur with the presence of stagnant water which acts as ideal breeding grounds for the organisms. Lack of proper sanitation and water supply are also causal factors for these 
diseases. Examples of thesediseases are scabies, skin sepsis, leprosy, trachoma, ascariasis, yaws, lice and thypus. Water-based diseases can be controlled by proper washing and cooking of food, as well as hygienic water supply systems.

Water-related vector diseases are caused when insect vectors or other animals who live in water bite or come in contact with humans. Water-related vectors are also caused by water stagnation, and poor sanitation; and they can be controlled with the use of pesticides to destroy the vectors, use of bed nets (for insect vectors), as well as use of natural predators of the vectors. With respect to the majority farming households in rural Nigeria; the use of sprinkler irrigation instead of building canals may reduce the prevalence of the insect vectors. These diseases include: schistosomiasis, dracunuliasis, filiarisis, and threadworm infections

Water-scarce diseases are diseases that arise when there is water scarcity. They thrive in the condition of inadequate access to water. Provision of adequate and sustained water supply for the population is the most important means of controlling for water scarce diseases. Diseases in this class include malaria, onchocerciasis, dengue fever and yellow fever.

\subsection{Health, Social and Economic Implications of Water-Related Neglected Tropical Diseases}

In general, neglected tropical diseases cause great deal of morbidity and in some cases lead to death. In actual situations, the consequences of NTDs are in terms of ill-health, social exclusion and economic downturn. Water-related NTDs lead to debilitating health conditions among the sufferers. For example, schistosomiasis is associated with blood in urine, nausea and pains. Onthe other hand, river blindness may lead to more permanent loss of eyesight if not treated urgently. Guinea worms like most other intestinal worms lead to intestinal disorders, weight loss, and anemia. People who suffer from elephantiasis have symptoms associate with lymphatic blockages that lead to painful enlargement of limbs. Women and children often suffer more from NTDs especially in African countries, because they are the 'voiceless". The effects of immediate infections with the NTDs are usually far reaching among this group; causing infertility, lesions, skin disorder and adult onset of blindness [24].

The social implication of these NTDs are more commonly seen in the exclusion of the sufferer from societal roles and responsibility. The disfiguration and blindness that result from the disease may lead to psychological trauma for the victims, [15].The damage may be drastic enough to totally exclude the sufferers and their households from economic, social and political activities within the community[25]

The economic implications of NTDs are perhaps more far reaching than expected. The health implications of NTDs make it difficult for sufferer to engage in their regular productive activities [26]. The continued loss of productive days make it difficult to seek for timely treatment, thereby leading to a vicious cycle of poverty and ill-health. Since they are usually associated with poor, rural agricultural households, NTDs as a whole reduce agricultural output, with far reaching effects on national food supply [27].

\subsection{Scope of the Study}

\section{Methodology}

The study made use of the nationwide National Demographic and Health Survey of 2008.The survey covered the 36 states of the county and the federal capital territory. The sampling frame for the survey was the 2006 National Population census of the National Population Commission. The survey made use of a 2 stage cluster sampling consisting of 888 clusters in the urban areas and 286 clusters in the rural areas. The clusters were formed on the basis of the Enumeration areas from the 2006 census. Each enumeration area is got by the division of the country into states, from states into local government areas and then into localities which formed the primary sampling unit. Households were randomly selected from the primary sampling units within the survey.

In the data, the neglected tropical diseases surveyed were water-related and more common in the rural area. Hence the use of the rural household data. Thus the data requirements for this study were:

i. Socioeconomic characteristics of the rural households

ii. Water and sanitation related characteristics of households

iii. Incidence of five NTDs, namely: River blindness, Elephantiasis, Guinea worm and Schistosomiasis

After solving for missing data, the total sample size for this study was 8004 households in rural Nigeria.

\subsection{Methods of Data Analysis}

The analysis in this study was mainly descriptive, with the aid of frequencies, tables and graph were employed to profile the incidence of NTDs across the different socioeconomic classifications of the rural households. Tests of differences using Chi2 was used to determine significant differences across groups. 


\section{Results And Discussion}

\subsection{Description of Socioeconomic and Demographic Characteristics of Rural Households in Nigeria}

Description of socioeconomic characteristics of the rural households is presented in this section. The resultsas presented in Table 1 shows that there are more male headed households, $91.5 \%$ than female headed households $(8.6 \%)$. About $35 \%$ of the household heads had primary education, while only $3.3 \%$ had higher education. Majority of the household heads were also married, (82.63\%), and only $13.2 \%$ were never married. Widowed and divorced household heads made up $3.29 \%$ and $0.89 \%$ respectively.

Classification into wealth quintiles showed that the majority of the rural households were in the poorest (34.43\%) and poor $(30.13 \%)$ wealth quintiles. Households in the middle wealth quintile were $24.29 \%$, while those in the rich and richest wealth quintile were $9.03 \%$ and $2.11 \%$ respectively. This further corroborate studies that maintain rural households as low income group, with low access to health care [28].The results also shows that only $28 \%$ of the rural households use bed nets to sleep at night. This means that the majority of the rural households were predisposed to insect bites during the night.The implication of this is that the household members are susceptible to diseases caused by water-related insect vectors such as elephantiasis $[29 ; 30]$.

Distribution by geopolitical zone reveals that the North-east zone $(37.17 \%)$ had the highest representation of rural households in Nigeria, followed by the North-Central zone (36 21\%). The North-West zone had $14.83 \%$ representation. The South-west, South-South and South-East zone had representation of $4.76 \%, 3.62 \%$ and $3.41 \%$, respectively. The average age of the household heads was $46.4 \pm 14.7$ years; while the average household size was $7.6 \pm 4.1$ persons.

Table 1:Socioeconomic and Demographic Characteristics of Rural Households

\begin{tabular}{|c|c|c|}
\hline Variable & Frequency/Average & Percentage \\
\hline \multicolumn{3}{|l|}{ Sex of household head } \\
\hline Male & 7320 & 91.45 \\
\hline Female & 684 & 8.55 \\
\hline \multicolumn{3}{|c|}{ Educational status of household head } \\
\hline Non Formal & 3500 & 4.73 \\
\hline Primary & 2809 & 35.09 \\
\hline Secondary & 1428 & 17.84 \\
\hline Higher & 267 & 3.34 \\
\hline \multicolumn{3}{|c|}{ Current marital status of household head } \\
\hline Never married & 1056 & 13.19 \\
\hline Married & 6614 & 82.63 \\
\hline Widowed & 263 & 3.29 \\
\hline Divorced & 71 & 0.89 \\
\hline \multicolumn{3}{|l|}{ Wealth Index } \\
\hline Poorest & 2756 & 34.43 \\
\hline Poor & 2412 & 30.13 \\
\hline Middle group & 1944 & 24.29 \\
\hline Rich & 723 & 9.03 \\
\hline Richest & 169 & 2.11 \\
\hline \multicolumn{3}{|l|}{ Use bed net for sleeping } \\
\hline Yes & 2252 & 28.14 \\
\hline No & 5752 & 71.86 \\
\hline \multicolumn{3}{|l|}{ Geopolitical Zone } \\
\hline North Central & 2898 & 36.21 \\
\hline North East & 2975 & 37.17 \\
\hline North West & 1187 & 14.83 \\
\hline South East & 290 & 3.62 \\
\hline South South & 273 & 3.41 \\
\hline South West & 381 & 4.76 \\
\hline Age of Household Head & $46.40(14.87)$ & \\
\hline Household size & $7.57 \quad 4.09)$ & \\
\hline
\end{tabular}

* Standard deviation in bracket

Source: Computation fromNational Demographic and Health Survey (NDHS), 2008

\subsection{Characteristics of Rural Households by Availability and Use of Water and Sanitation Facilities}

This section examines the availability of water for domestic use by the households. The results are presented in Table 2. The results shows that about $82 \%$ of the rural households needed to source for their domestic water use from outside of their immediate living vicinity. Also, the result shows that a larger percentage of the rural households $(66.82 \%)$, drank water from unprotected sources such as open wells, springs and streams. This is expected to predispose the householdmembers to water-related diseases in general and water-related NTDs in particular. Furthermore, Table 2 shows that $83.65 \%$ of the rural households did not subjecttheir domestic water to any kind of treatment. When type of water treatment was further required, the results showed that straining and the use of alum for traditional sedimentation of water was the most popular 
treatment method used $(5.15 \%$ and $4.97 \%$, respectively). Only a very small proportion of the households used improved water treatment methods such as boiling, water filters and chemical treatment, $(3.97 \%, 3.01 \%$ and $0.97 \%$ respectively). This suggests that water utilization by rural households is usually in the untreated state, which most likely contains disease causing organisms, with negative implications for the health of the household members [31].

With respect to household sanitation facilities, the results shows that majority $(49.81 \%$ ) of the household do not have any toilet facilities, while $29.47 \%$ use covered pit latrine. The use of uncovered pit latrine and/or buckets was seen among $18.64 \%$ of the households, while only $2.07 \%$ had access to the use of proper sanitary facilities such as flush toilets. The implication of this is that most of the rural households will tend to resort to the use of bushes and water bodies to dispose of their waste materials also found in a recent study by [32]. This has grave implications for public health issues for the rural communities, especially as regards waterrelated neglected tropical diseases.

Table 2: Profile of Rural Households by Water and Sanitation Facilities

\begin{tabular}{lll}
\hline Variable & Frequency & Percentage \\
\hline Location of source of water for domestic use & & 18.03 \\
Within household dwelling & 1443 & 81.97 \\
Outside household dwelling & 6561 & 33.18 \\
Type of Drinking water & & 66.82 \\
Protected pipes, or well & 2656 & 16.35 \\
Non protected (Streams, open wells, rain water) & 5348 & 83.65 \\
Is water treated before use? & & \\
Yes & 1309 & 83.65 \\
No & 6695 & 1.52 \\
Type of water treatment used & & 3.01 \\
None & 6695 & 5.15 \\
Boiling & 122 & 0.97 \\
Using bleach & 241 & 0.01 \\
Straining & 412 & 0.71 \\
Water filter machine & 78 & 4.97 \\
Solar purification & 1 & \\
Natural sedimentation & 57 & 49.81 \\
Use of alum & 398 & 18.64 \\
Type of toilet facility available & & 29.47 \\
None & 3987 & 2.07 \\
Uncovered pits/buckets & 1492 & 2008 \\
Covered pit latrines & 2359 & 166 \\
Flush toilet & 166 & \\
\hline Computation from National & & \\
\hline
\end{tabular}

\section{Source: Computation fromNational Demographic and Health Survey (NDHS), 2008}

\subsection{Profile of Rural Households by Incidence of Water- Related NTDs}

The incidence of water-related NTDs in rural Nigeria is presented in Fig. 1. The findings showed that the most prevalent NTD in rural Nigeria was river blindness, (61.97\%), followed by schistosomiasis at $22.34 \%$ and elephantiasis at $13.12 \%$. The least occurring of the water-related NTDs was guinea worm (about 3\%). This shows that the burden of water-related NTDs in Nigeria is mainly hinged on debilitating conditions such as blindness and disfiguration that lead to loss of productive capacity of the affected individuals. The low incidence of guinea worm infestation is evidence of previous campaigns to stamp out it out Nigeria by past government administrations, [33].

Figure 1: Percentage Distribution of Incidence of Water-Related Neglected Tropical Diseases in Rural Nigeria

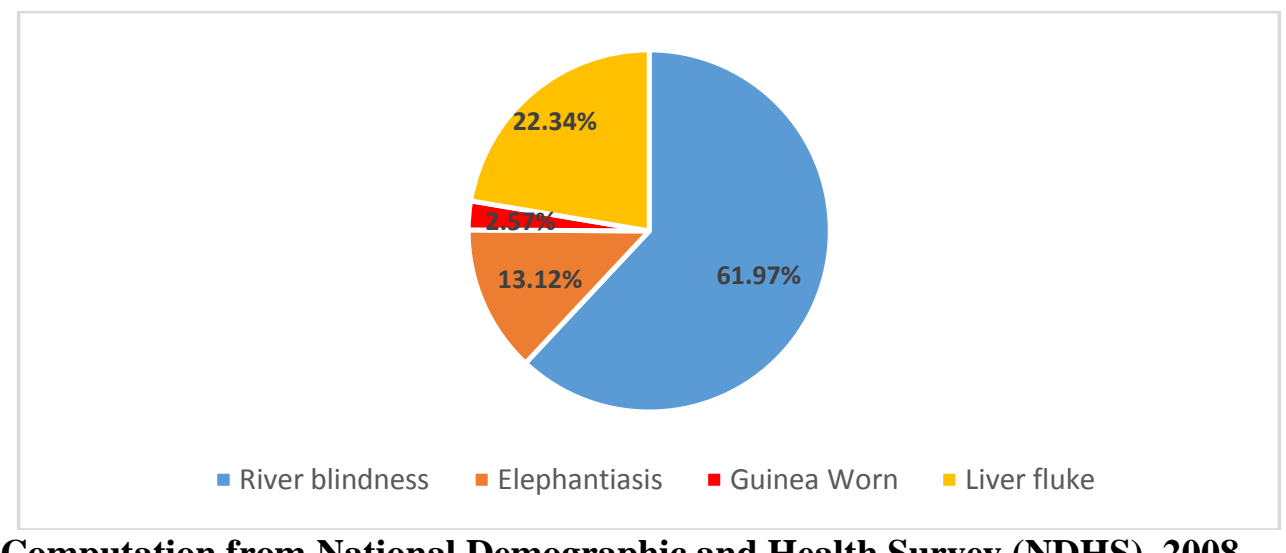

Source: Computation from National Demographic and Health Survey (NDHS), 2008 


\subsection{Profile of Water-related NTDs by Household Level Socioeconomic and Demographic Characteristics}

Table 3 shows the results of incidence of the water-related NTDs by household socioeconomic and demographic characteristics. The results shows that male headed households have members with higher incidences of the four water-related NTDs than female headed households. Also, higher levels of education of the household heads had reducing effect on the incidences of the NTDs in rural Nigeria. In all cases we found that households whose heads have non-formal education had highest incidence of all the diseases, with the highest incidence noted for guinea worm (48.54\%), and followed by schistosomiasis (47.48\%). For households with primary educations, the highest incidence of water-related NTDs was schistosomiasis (37.71\%); followed by elephantiasis $(37.33 \%)$. However, for household heads with secondary education and higher education, the NTD with the highest incidence was elephantiasis (20.57\%) and river blindness respectively (3.97\%).

With respect to the wealth status of the households, the result revealed progressive reduction in the incidence of all the water-related NTDs with increased wealth status. The poorest households had the highest incidence of all the NTDS. However, the most prevalent water related NTD for households in the poorest wealth quintile was found to be schistosomiasis ( $45.81 \%$ ), while it was elephantiasis (35.\%) for households in the poor wealth quintile. Households in the middle wealth status groups had guinea worm as the most prevalent waterrelated NTD occurring. Households in the rich and richest groups however had river blindness as the most occurring water-related NTD $(10.96 \%$ and $2.66 \%$ respectively). The results suggests that the rural households who are usually in the poorest quintile in Nigeria are more susceptible to infections and become symptomatic with regards to the water-related NTDs. This may be as a result of poor living conditions as well as inability to access fast and good health care services [34].

When incidence of occurrence of the NTDs were examined by geopolitical zone, the result shows that water-related NTDs have higher incidence of occurrence in Northern Nigeria than in the southern zone. For all the NTDs, except river blindness, the north central zone had the highest incidence of occurrence, while the South-South zone had the lowest. Moreover, the NTDs with the highest incidence of occurrence in the NorthCentral zone, north east and North-West zones were elephantiasis, river blindness and guinea worm respectively.

Table 3:Distribution of Incidence of Water-Related Neglected Tropical Diseases by Household Socioeconomic and Demographic Characteristics

\begin{tabular}{|c|c|c|c|c|c|}
\hline \multirow{2}{*}{ Variable } & \multicolumn{4}{|c|}{ Percentage incidence of water-related Neglected Tropical Diseases } & \multirow{2}{*}{$\begin{array}{ll}\text { Test } & \text { of } \\
\text { Differences }\end{array}$} \\
\hline & River blindness & Elephantiasis & Guinea Worm & Schistosomiasis & \\
\hline \multicolumn{6}{|c|}{$\begin{array}{l}\text { Sex of household } \\
\text { head }\end{array}$} \\
\hline Male & 91.13 & 90.48 & 93.20 & 92.73 & $6.48^{*}$ \\
\hline Female & 8.87 & 9.52 & 6.80 & 7.27 & \\
\hline \multicolumn{6}{|c|}{$\begin{array}{l}\text { Educational status } \\
\text { of household head }\end{array}$} \\
\hline Non Formal & 43.25 & 38.67 & 48.54 & 47.48 & $73.67 * * *$ \\
\hline Primary & 33.81 & 37.33 & 32.04 & 37.70 & \\
\hline Secondary & 18.97 & 20.57 & 17.96 & 13.09 & \\
\hline Higher & 3.97 & 3.43 & 1.46 & 1.73 & \\
\hline \multicolumn{6}{|l|}{ Wealth status } \\
\hline Poorest & 31.25 & 30.67 & 31.55 & 45.81 & $273.9 * * *$ \\
\hline Poor & 27.70 & 38.00 & 34.95 & 31.71 & \\
\hline Middle group & 27.40 & 21.52 & 27.67 & 16.89 & \\
\hline Rich & 10.99 & 7.43 & 5.34 & 4.98 & \\
\hline Richest & 2.66 & 2.38 & 0.49 & 0.62 & \\
\hline \multicolumn{6}{|c|}{$\begin{array}{l}\text { Use bed net for } \\
\text { sleeping }\end{array}$} \\
\hline Yes & 72.08 & 69.81 & 74.27 & 72.20 & 3.00 \\
\hline No & 27.92 & 30.91 & 25.73 & 27.80 & \\
\hline \multicolumn{6}{|c|}{ Geopolitical Zone } \\
\hline North Central & 28.02 & 58.86 & 43.69 & 44.74 & $636.11 * * *$ \\
\hline North East & 42.94 & 27.14 & 26.21 & 28.30 & \\
\hline North West & 13.69 & 8.38 & 18.93 & 21.31 & \\
\hline South East & 4.33 & 2.48 & 3.88 & 2.29 & \\
\hline South South & 4.52 & 1.52 & 2.91 & 1.51 & \\
\hline South West & 6.49 & 1.62 & 4.37 & 1.85 & \\
\hline
\end{tabular}

Source: Computation from National Demographic and Health Survey (NDHS) data, 2008

\subsection{Profile of Wate- Related NTDs by Household Water use and Sanitation Characteristicsin rural Nigeria}

Table 4 shows the description of incidence of water-related NTDs in rural Nigeria by the availability and use of water and sanitary facilities. We find that incidence of all the NTDs reported increased with location of source of water located outside the dwelling vicinity of the households. This is especially so with respect to 
river blindness $(83.23 \%)$ and schistosomiasis $(82.05 \%)$. The transmission of these diseases occurs with insect vectors that reside in areas with dirty and non-moving water. Moreover, with respect to source of drinking water, the results shows that guinea worm has high incidence with non-protected water sources $(70.87 \%)$, followed by elephantiasis $(70.19 \%)$. Literature has shown that the guinea worm is transmitted when water that has been contaminated with the worm is ingested. [35].

When the incidence of occurrence was profiled by type of water treatment used, the results show that for those who claim too use some form of water treatment, incidence of occurrence of all four water-related NTDs was highest for those who use alum as water treatment. This corroborates the study by where use of alum as sole water treatment was associated with increased incidence of water borne diseases [36].

The results also shows that the incidence of occurrence of the NTDs increased with worsening condition of sanitation facilities. Thus, in conjunction with improved water supply, improved sanitation is important in combating the NTDs in rural areas [16]. The sustainability of water and sanitation facilities by ensuing inclusive participation of government and communities will go a long way in ensuring a reduction in the incidence of occurrence of these water-related NTDs [37].

Table 4: Distribution of Incidence of Water-Related Neglected Tropical Diseases by Household Water Use and Sanitation Characteristics

\begin{tabular}{|c|c|c|c|c|c|}
\hline \multirow[t]{2}{*}{ Variables } & \multicolumn{4}{|c|}{ Percentage incidence of water-related Neglected Tropical Diseases } & \multirow{2}{*}{$\begin{array}{l}\text { Test } 0 \\
\text { differences }\end{array}$} \\
\hline & $\begin{array}{l}\text { River } \\
\text { blindness }\end{array}$ & Elephantiasis & Guinea Worm & Schistosomiasis & \\
\hline \multicolumn{6}{|l|}{$\begin{array}{l}\text { Location of source of water for } \\
\text { domestic use }\end{array}$} \\
\hline Within household dwelling & 16.77 & 23.14 & 22.82 & 17.95 & \multirow[t]{2}{*}{$27.1 * * *$} \\
\hline Outside household dwelling & 83.23 & 78.86 & 77.18 & 82.05 & \\
\hline \multicolumn{6}{|l|}{ Type of Drinking water } \\
\hline Protected sources & 33.59 & 29.81 & 29.13 & 34.51 & \multirow[t]{2}{*}{$8.70 * *$} \\
\hline $\begin{array}{l}\text { Non protected sources (Streams, } \\
\text { open wells, rain water) }\end{array}$ & 66.41 & 70.19 & 70.87 & 65.49 & \\
\hline \multicolumn{6}{|l|}{ Is water treated before use? } \\
\hline Yes & 14.64 & 20.19 & 25.73 & 17.79 & \multirow{2}{*}{$37.9 * * *$} \\
\hline No & 85.36 & 79.81 & 74.27 & 82.21 & \\
\hline \multicolumn{6}{|l|}{ Type of water treatment used } \\
\hline None & 85.36 & 79.81 & 74.27 & 82.21 & \multirow[t]{8}{*}{$220.0 * * *$} \\
\hline Boiling & 1.27 & 0.48 & 0.49 & 2.96 & \\
\hline Using bleach & 2.20 & 4.10 & 9.22 & 3.91 & \\
\hline Straining & 4.19 & 6.57 & 4.37 & 7.05 & \\
\hline Water filter machine & 0.71 & 1.71 & 0.97 & 1.29 & \\
\hline Solar purification & 0.02 & 0.00 & 0.00 & 0.00 & \\
\hline Natural sedimentation & 0.34 & 1.14 & 1.94 & 1.34 & \\
\hline Use of alum & 5.91 & 6.19 & 8.74 & 1.23 & \\
\hline \multicolumn{6}{|l|}{ Type of toilet facility available } \\
\hline None & 2.60 & 27.54 & 21.90 & 47.96 & \multirow[t]{4}{*}{$180.8^{* * * *}$} \\
\hline Uncovered pits/buckets & 2.10 & 36.29 & 17.14 & 44.48 & \\
\hline Covered pit latrines & 3.88 & 23.79 & 14.08 & 58.25 & \\
\hline Flush toilet & 0.39 & 31.49 & 11.02 & 57.10 & \\
\hline
\end{tabular}

Legend: **; *** are significant levels at $5 \%$ and $1 \%$ respectively

Source: computed from National Demographic and Health Survey (NDHS), 2008

\section{Conclusion And Policy Recommendations}

The research study explored the incidence of water-related neglected tropical diseases in rural Nigeria, using data from the demographic and health survey of 2008 for Nigeria. The study found incidence of occurrence of four water-related NTDs in rural Nigeria. These NTDs were highly correlated with low educational status of head of households as well as poverty.

Also, in light of the above, the study found that lack of access to portable water supply and sanitation was correlated with the incidences of occurrence of four water-related NTDs in rural Nigeria. Recognizing the importance of wholesome water thus important in developing appropriate interventions towards eliminating the NTDs.The study concludes that water-related NTDs in rural Nigeria thrive in the presence of inadequate access to portable water for household use. This is also an indirect consequence of poverty and low level of political voice of the rural farm families. This study therefore recommends that literacy and education be emphasized among rural based households. This is expected to lead to better awareness of the use of safe water and sanitation for household use.Moreover, there is a need for sustained supply of portable water for use by rural households. The continued supply of safe water should however be the purview of all stakeholders-government, private sector and the rural communities themselves. Ownership of resources by the local community has been shown to lead to more sustainable use of such resources. 


\section{References}

[1] Hotez, P. J. (2011). The neglected tropical diseases and the neglected infections of poverty: overview of their common features, global disease burden and distribution, new control tools, and prospects for disease elimination. The causes and impacts of neglected tropical and zoonotic diseases: Opportunities for integrated intervention strategies, 221

[2] Akali, D. M., Iorhemen, O. T., Otun J. A., and Alfa M. I., (2014). Provision of Sustainable Water Supply System in Nigeria: A Case Study of Wannune-Benue State. World Journal of Environmental Engineering, 2(1), pp: 1-5.

[3] Stanwell-Smith, R. (2009). CLASSIFICATION OF WATER-RELATED DISEASE. In Water and Health-Volume I, 66, 2009.

[4] World Health Organization (WHO), 2011), "Technical Guidance on Water Related Disease Surveillance'. Protocol on Water and Health, World Health Organization Regional Office for Europe, 2011.

[5] Nwabor O. F.., Nnamonu E.I., Martins P. E. and Ani O. C., 2016, 'Water and Water Borne Diseases: a Review'. International Journal of Tropical Diseases and Health. 12(4);1-14.

[6] Centre for Diseases Control (CDC), 2017, 'Neglected Tropical Diseases'. Retrieved online from https://www.cdc.gov/globalhealth/ntd/ on 26/06/2017.

[7] Hotez P.J., Kamath A., (2009). Neglected tropical diseases in sub-Saharan Africa: review of their prevalence, distribution, and disease burden. PLoS Neglected Tropical Diseases 2009, 3(8):e412.

[8] IOM (Institute of Medicine). 2011. The Causes and Impacts of Neglected Tropical and Zoonotic Diseases: Opportunities for Integrated Intervention Strategies. Washington, DC: The National Academies Press.

[9] Deribe K., Meribo K., Gebre T., Ali A., Aseffa A., and Davey G., (2010), 'The Burden of Neglected Tropical Diseases in Ethiopia, and Opportunities for Integrated Control and Elimination'. Parasites and Vectors, 5 (240): 1-15.

[10] World Health Organization, (2011): Neglected Tropical Diseases: Diseases covered by the NTD department. WHO Internet resources, 2011.

[11] Conteh L, Engels T and Molyneux D. H., (2010): Socioeconomic Aspects of neglected tropical diseases. The Lancet Journal, 375( 9710):239-247, doi: 10.1016/S0140-6736(09)61422-7

[12] Nwoke E.A. and Nwoke B.E., (2013). Neglected Tropical Diseases need more than Money. International Journal of Diseases and Disorders, 1(4):47-52.

[13] Simon, G. G. (2016). Impacts of neglected tropical disease on incidence and progression of HIV/AIDS, tuberculosis, and malaria: scientific links. International Journal of Infectious Diseases, 42: 54-57.

[14] Muela Ribera J, PeetersGrietens K, Toomer E, and Hausmann-Muela S (2009), 'A Word of Caution against the Stigma Trend in Neglected Tropical Disease Research and Control'. PLoS Neglected Tropical Diseases,3(10) e445. https://doi.org/10.1371/journal.pntd.0000445

[15] Skolnik Richard and Ahmed Ambareem, (2010): Ending the Neglect of Neglected Tropical Diseases. Population Reference Bureau, Policy Brief, February, 2010.

[16] World Health Organization (WHO), (2015).Investing to overcome the Global Impact of Neglected Tropical Diseases.Third WHO report on Neglected Tropical Diseases. WHO, Geneva, 2015.

[17] Ako A. A., Nkeng G. E., and Takem G. E., (2009). Water Quality and Occurrence of Water-Borne Diseases in the Douala $4^{\text {th }}$ District, Cameroon. Water Science Technology Journal, 59(12): 2321-2329.

[18] Prüss-Üstün A, Bos R, Gore F, Bartram J., (2008). Safer water, better health: costs, benefits and sustainability ofinterventions to protect and promote health. World Health Organization, Geneva, 2008

[19] UNICEF, (2008). Water and Sanitation Summary Sheet- Nigeria. Water and Sanitation Summary. Platform, 2008.

[20] Ibok, E. E., and Daniel, E. E. (2014). Rural Water Supply and Sustainable Development in Nigeria: A Case Analysis of Akwa Ibom State. American Journal of Rural Development, 2(4): 68-73.

[21] Galadima, A., Z. N. Garba, L. Leke, M. N. Almustapha, and I. K. Adam, (2011) Domestic Water Pollution among Local Communities in Nigeria----Causes and Consequences. European Journal of Scientific Research 52(4): 592-603.

[22] Federal Government of Nigeria (FGN), (2012), Nigeria Master Plan for Neglected Tropical Diseases (NTDs):2013-2017. Federal Government of Nigeria, March 2012.

[23] Hatami H, (2013). Importance of Water and Water Borne Diseases: on the Occasion of World Water Day (March 22, 2013). International Journal of Preventive Medicine, 3: 243-245.

[24] McDonald, M. (2011). Neglected tropical and zoonotic diseases and their impact on women's and children's health. In The causes and impacts of neglected tropical and zoonotic diseases: Opportunities for integrated intervention strategies, pp: 357-388. 
[25] Gyapong, M., Nartey, A., Oti, E., and Page, S. (2016). The Social and Economic Impact of Neglected Tropical Diseases in Sub-Saharan Africa. In Neglected Tropical Diseases-Sub-Saharan Africa (pp. 349365). Springer International Publishing.

[26] Hotez, P. J., and Herricks, J. R. (2015). Impact of the neglected tropical diseases on human development in the Organisation of Islamic Cooperation Nations. PLoS neglected tropical diseases, 9(11), e0003782.

[27] Norris, J., Adelman, C., Spantchak, Y., and Marano, K. (2012). Social and Economic Impact Review on Neglected Tropical Diseases. Economic Policy/Briefing Paper. Washington DC: Hudson Institute.

[28] Janssens, W., Goedecke, J., De Bree, G. J., Aderibigbe, S. A., Akande, T. M., \&Mesnard, A. (2016). The Financial Burden of Non-Communicable Chronic Diseases in Rural Nigeria: Wealth and Gender Heterogeneity in Health Care Utilization and Health Expenditures. PloS one, 11(11), e0166121.

[29] Lenhart, A., Orelus, N., Maskill, R., Alexander, N., Streit, T., and McCall, P. J. (2008). Insecticide-Treated Bed Nets to Control Dengue Vectors: Preliminary Evidence from a Controlled Trial in Haiti. Tropical Medicine \& International Health, 13(1), 56-67.

[30] Wilson A.L., Dhiman R.C., Kitron U., Scott T.W., Vane de berg H., and Lindsay S. W., (2014). Benefits of insecticide-Treated Nets, Curtains and Screening on Vector Borne Diseases, Excluding Malaria: a Systematic Review and Meta-analysis. PLOS Neglected Tropical Diseases, 8 (10): 1-13.

[31] Muta'aHellandendu, J., (2012). Health implications of water scarcity in Nigeria. European Scientific Journal, Vol 8 (18): 111-117.

[32] Ordinioha, B., \&Owhondah, G. (2008). Sanitation facilities and hygiene practices in a semiurban community in Rivers State, south-south Nigeria. Nigerian Health Journal, 8(1-2), 1015.Nigerian Centre for Disease Control (NCDC), (2017). Guinea Worm Disease. Retrieved online from http://www.ncdc.gov.ng/diseases/info, on 26/06/2017.

[33] Fagbamigbe, A. F., Bamgboye, E. A., Yusuf, B. O., Akinyemi, J. O., Issa, B. K., Ngige, E., ... \&Abatta, E. (2015). The Nigeria wealth distribution and health seeking behaviour: evidence from the 2012 national HIV/AIDS and reproductive health survey. Health economics review, 5(5): 1-10. doi:10.1186/s13561015-0043-9

[34] Greenaway, C. (2004). Dracunculiasis (guinea worm disease). Canadian Medical Association Journal, 170(4), 495-500

[35] Oguntoke O., Aboderin O.J. and Bankole A. M., (2009). Association of Water-Borne Disease Morbidity Pattern and Water Quality in Parts of Ibadan City, Nigeria. Tanzanian Journal of Health Research, 11(4): 189-195.

[36] Ademiluyi, I. A., \&Odugbesan, J. A. (2008). Sustainability and impact of community water supply and sanitation programmes in Nigeria: An overview. African Journal of Agricultural Research, 3(12): 811817.

\footnotetext{
Temitayo Adenike Adeyemo. "Estimating the Incidence of Water Related Diseases: the case of Neglected Tropical Diseases in Rural Nigeria." IOSR Journal of Agriculture and Veterinary Science (IOSR-JAVS) 10.7 (2017): 49-57
} 